\title{
Discussion on the Influence of Network Sports Information on College Students' Sports Life Style
}

\author{
Yan Gong ${ }^{1, a}$ \\ ${ }^{1}$ Jiangxi Science and Technology Normal University, Nanchang, Jiangxi, China, 330003 \\ ${ }^{a}$ email,
}

Keywords: Network Sports Information; College Students' Sports Life; Influence

\begin{abstract}
With the continuous development and widely using of the network, network information began to penetrate into various fields and each region to promote a good blend of world culture, and also makes our access to information resources continue to expand. The sports information in the network information greatly promoted the development of Chinese sports industry and also changed the sports life of college students in China. This paper takes the network information as the research background, discusses the influence of the network sports information on the college students 'sports life style, and uses the scientific research method to study the influence of the network sports information on the college students' sports life style.
\end{abstract}

\section{Introduction}

With the continuous development of Chinese network of information technology, network information has brought great convenience to people's lives, the network platform to become the main channel for the masses to obtain outside information. According to the latest "China Internet Development Statistics Report", the network is rapidly popularizing and quoting in education, social, entertainment and other fields, college students thinking active, easy to accept new things, become the most active group of network use. Through the network to obtain sports information to become the main channel for college students to obtain sports news, network communication for college students' sports fans to bring a more efficient, more comprehensive and more convenient sports information. Today, network and multimedia technology continue to deep into the process of college physical education, the network sports environment has become the most popular college students' sports environment.

\section{The Effective Analysis of College Students' Sports Life Style}

The Development of Network Sports Information. Network sports information has become the main way to develop sports in China. Network news has gained the love of different people by virtue of the characteristics of high efficiency, convenience and fact, and gradually replaced the traditional media people to obtain the main channel of sports information. The development of online sports subtle changes in the original sports life of college students, college students through the network sports news to understand the most developed at home and abroad, the most advanced and the most time-sensitive and forward-looking sports information, and cultivate a large number of sports enthusiasts The Network information coverage of the more comprehensive resources, real-time broadcast of the event makes the information with the best timeliness, the host commentary for college students to provide a wide range of how good the level of sports insights. By watching the corresponding real-time events, health counseling to carry out sports activities, is conducive to cultivating the correct sports values of college students [1].

The Network Sports Information Changes the College Students' Sports Values. The application of network sports information not only increases the channel of college students to obtain sports information, but also changes the original sports concept of college students. The concept of sports values is often mentioned in physical education, is that people according to their own different, made a subjective evaluation of sports. College students sports values refers to the performance of college students on the movement of sports is the degree of college students love 
the sport, this love in the later will be transformed into the habit of physical exercise and behavior.

In the past, the teaching of college physical education mainly regards the students 'mastery of sports skills as the teaching purpose, and takes the students' assessment rate of sports as the physical education teacher. Weekly physical education for those who want to sports on the students, unable to meet the needs of college students' sports enthusiasts, such a pattern of physical education makes the values of sports college students gradually changed. The spread of network sports information for students to understand sports knowledge, learning sports skills to provide a convenient. According to the different physical condition of each student, they can plan their own training plan. According to the relevant data, the abundance of network sports information breaks the dilemma of lack of physical activity, and female college students often appear in the playground for long and short run. Physical exercise is not a single athletic, more physical fitness, entertainment, and even dating way. Network sports information makes the formation of college students 'awareness of physical exercise, making the college students' sports values more diversified development, the formation of integrated, diversified sports values.

The Development of Sports Awareness. College students' awareness of physical exercise in the popularity of network sports information in a good direction continues to develop. In the traditional mode of physical education, due to the single teaching mode, the boring style of training, so that students have been in a passive acceptance of the state. Network sports information is rich and updated, can attract more students to learn sports knowledge. The real-time broadcast of the network sports is an innovative change brought by the sports development. The college students cultivate the better sports spirit by watching the game, understanding the hardships of the athletes and realizing the tough sports spirit [2].

\section{The Impact of Network Sports Information on the Sports Life Style of College Students}

The New Sports under the Network Era - the Electronic Sports. Each sport is a culture, with the development of the Internet age, e-sports was born to the basis of online games, through the operation of the relevant game. In 2003, the State Sports General Administration officially put the e-sports into our sports, so that those who like sports games to join the sport, the data show that $85.4 \%$ of college boys and $50.3 \%$ of girls often participate in e-sports, according to game type E-sports is divided into tactical game era, the strategic game era, which is mainly shooting game. E-sports requires athletes to have a strong response speed, efficient teamwork and flexible teamwork, and the need for certain tactical command. The survey shows that college students now play sports games with live soccer, heroes and other competitive games and college students can through the game to enhance their communication skills, tactical command ability, and exercise their own sports spirit. E-sports began to be recognized by the people at the same time, and even began to continue to develop, and gradually accepted by others, which e-sports began to exist very early, has been misunderstood, the traditional concept of playing games is a miserable thing, is willing to fall. According to the data show that $30.5 \%$ of college students play games every day more than 3 hours, 56\% of college students think that playing games affect their own work and rest.

The Development of Network for College Students to Obtain Sports Information Resources. Network sports information through text, pictures, animation, video and other different ways to combine $\mathrm{t}$ information together, the formation of a wide range of colorful news consulting. Through the network of college students can not only simple access to sports skills, sports knowledge, but also concerned about the relevant sports events for real-time broadcast. Of which $21.6 \%$ of male college students through the network to learn the appropriate skills, while girls learn sports skills only $1.3 \%$ of girls. As the girls of the physiological period and beauty of the nature, they are keen on weight-loss exercise and knowledge of human health knowledge. With the continuous development of network information technology, database, cloud data innovation makes the network data is growing, the relevant information shows that the network on the sports page has been over a hundred million, this billion sports reports to form a huge sports resources, on the network of sports advice constantly updated, every moment there are sports news updates. Through the network, college students on sports news, knowledge, products have a certain understanding. 
The Impact of Network Information on College Students' Sports Associations. University societies, as a small sports organization, play an important role in college students 'sports life. Societies organize sports competitions. Physical training has gradually become the guide for college students' physical exercise. Badminton clubs, basketball clubs, soccer clubs and other communities to attract a variety of sports enthusiasts, various associations to carry out the corresponding community activities to improve the development of community athletes. Network as a fast and convenient way of social networking, it provides the convenience for the development of college students to. Different from the actual college students' community, we will be on the network of college students sports associations are divided into sports culture exchange class organization, sports and technical exchanges, organizations involved in sports. Which sports and cultural exchanges are mostly on the sports stars of the hot topics, such as Liu Xiang leg injury, Li Na game state is poor, the US NBA star, the World Cup and other topics, these topics are recently and what happened at that time. Network sports technology exchange is about technology, college students to exchange technology, the content is the daily life of college students' movement, mainly: roller skating technology, hip-hop sports practice, running cool experience sharing and college students now the most popular sports skills video. Network is produced in the exchange organization is the organization of activities, such activities to resource-based, for the whole school students, such an organization of mobility, members are uncertain, but the effective development of physical exercise. The creation of these network organizations to help students form a good exchange of sports enthusiasts, sports information resources can be shared, subversion of traditional organizational development, college sports organizations to provide another direction [3].

\section{The Related Recommendations for Development of College Students Sports Life}

Improve the Way of Physical Education. The continuous development of network information network should be reformed in college physical education. According to the relevant adjustment, college students in the university to accept the knowledge of $60 \%$ is to come with extracurricular, and $32 \%$ of which is through the network, make full use of the network for the construction of physical education.

Network sports education is a new type of education method, the construction of network sports should be the main way and the main way of college students to study. Schools and physical education teachers should be able to create conditions for college students to provide the appropriate network platform, according to the students of different sports interests, the development of different sports, the traditional education in the concept of student-oriented introduction. Now the college physical education must meet the students' physical and mental development.

Reasonable Constraints of Electronic Sports. Online games and e-sports both difficult to divide the boundaries, especially for freshman, sophomore new students, just entered the university as a result of the school is not heavy, time and other reasons, through the Internet to pass the time to form a certain addiction The E-sports to become Chinese sports, e-sports to college students, take the industrialization and professionalism of the road will inevitably. How to plan the relationship between the two is imperative, for college students to play online games, we must do about two points, on the one hand is to develop their own good habits, the formation of certain constraints on their own lives. Second, cultivate the self-discipline of college students, although the rich resources on the network but there are some bad resources, students need to effectively restrain themselves and resist the temptation to effectively resist the addiction.

\section{Conclusion}

The continuous development of the Internet age makes network information become part of the life of college students. The network information has become a great way for college students to understand sports knowledge and master sports skills, and the network information has become a great way to change the sports life style of college students. It makes college students know about 
sports using the network rather than addicted to online games. Establish the right sports value and make plane for physical education.

\section{References}

[1] Huang Meirong, Hu Rendong. Study on the Predicament of College Students' Sports Life in China - Based on the View of Higher Education Values [J]. Journal of Sports and Science, 2015,12(2):57-62.

[2] Chen Shuang, Ren Yuanjin. Effects of Mass Media Sports Information on College Students' Sports Behavior [J]. Journal of Anqing Teachers College (Natural Science Edition), 2007, 7(4): 110-112.

[3] Li Aijin. Investigation on the Fitness Condition of College Students in Guangdong Independent College - A Case Study of Southern Business School of Guangdong University of Foreign Studies[J]. Journal of Nanjing Institute of Physical Education (Natural Science Edition), 2011, 10(4): 111-113. 